\title{
Determining Patients' Satisfaction Level With Hospital Emergency Rooms in Iran: A Meta-Analysis
}

\author{
Vida Kardanmoghadam ${ }^{1}$, Nima Movahednia ${ }^{2}$, Mahtab Movahednia ${ }^{2}$, Mahmood Nekoei-Moghadam ${ }^{1}$, \\ Mohammadreza Amiresmaili ${ }^{1}$, Mahmood Moosazadeh ${ }^{3} \&$ Hossein Kardanmoghaddam $^{4}$ \\ ${ }^{1}$ Research Center for Health Services Administration, Institute of Future Studies in Health, Kerman University \\ of Medical Sciences, Kerman, Iran \\ ${ }^{2}$ Zabol University of Medical Sciences, Zabol, Iran \\ ${ }^{3}$ Health Sciences Research Center, School of Health, Mazandaran University of Medical Sciences, Sari, Iran \\ ${ }^{4}$ Faculty Member of Birjand University of Technology, Birjand, Iran \\ Correspondence: Mahmood Moosazadeh, Health Sciences Research Center, School of Health, Mazandaran \\ University of Medical Sciences, Sari, Iran. Tel: 98-911-355-5367. E-mail: mmoosazadeh1351@gmail.com
}

Received: October 30, 2014 Accepted: January 4, 2015 Online Published: January 14, 2014

doi:10.5539/gjhs.v7n4p260 URL: http://dx.doi.org/10.5539/gjhs.v7n4p260

\begin{abstract}
Emergency department is one of the important parts of hospitals, and patients' satisfaction with this department significantly affects their overall satisfaction with the hospital. Therefore, evaluating patients' satisfaction level with the emergency part has been taken into account in different studies. The purpose of this study was to systematically review all available primary studies and their results and to evaluate patients' satisfaction level with emergency rooms of hospitals. In this study, previous documents were reviewed; to do this, national and international databases were searched electronically and related articles were extracted. Reference list of the published studies were also reviewed to increase sensitivity and to select a greater number of articles. Reviewing and studying titles and texts of the articles, repeated and unrelated cases were excluded. The remaining articles were entered into stat aver., 11 for meta-analysis. After meta-analysis, 24 articles were selected. The lowest and highest satisfaction level was 24 and $98.4 \%$ respectively. Meta-analysis results of studies showed that general evaluation of patients' satisfaction level with emergency rooms of hospitals was $68.9 \%$ in Iran. This meta-analysis revealed that patients' satisfaction level with performance and with the way services were presented in emergency rooms of hospitals was desirable in Iran. Concerning multifactorial nature of patients' satisfaction, it is necessary to take this matter into regular and routine consideration.
\end{abstract}

Keywords: patients' satisfaction, emergency, hospital, meta-analysis

\section{Introduction}

Emergency department is one of the important hospital departments whose performance affects performance of other parts of the hospital (Yekkeh, 2006). Emergency centers, as a part of a system presenting health services in the society, play an important role in satisfaction of health service consumers (Moosazadeh, Nekoei-moghadam, \& Amiresmaili, 2013); that is; satisfaction level can improve by improving quality and by meeting expectations and needs of service receivers (Gilleard \& Reed, 1998).

Satisfaction is the basis for selecting the emergency department by the patient or recommending a certain emergency department to other patients (Lau, 2000). Satisfaction with emergency department increases total satisfaction with the organizations that provide medical services (Carter, Pouch, \& Larson, 2013). In recent decades, the number of people referring to emergency centers has increased; it is bad for patients' safety and affects quality of care (Gilleard, \& Reed, 1998; Ivy et al., 2013). Moreover, being aware of patients' perception of medical needs and emergencies helps emergency nurses evaluate and classify patients (Ekwall, 2013). Patients and people's viewpoints must be taken into account in order to improve quality of services (Amiresmaili \& Moosazadeh, 2013).

In studies conducted in different countries, evaluating patient's satisfaction has been emphasized in order to improve the quality of services (Moosazadeh, Nekoei-moghadam, \& Amiresmaili, 2013; Gilleard \& Reed, 1998; Lau, 2000; Carter, Pouch, \& Larson, 2013; Ivy et al., 2013). In a study conducted at a hospital in Virginia, 87.9\% 
of patients were satisfied with services they had received; he also stated that gender, place of living, education level, marital status, age and income were the factors that affected patient's satisfaction (Mackinley \& Roberts, 2001). In another study carried out in Kentucky, America on satisfaction level of 1056 patients with nursing attentions, it was shown that $84 \%$ were satisfied with nursing services (Trout, Magnusson, \& Hedges, 2000).

In his study in Qazvin in 2000, Shaikhi and Javadi reported that patients' satisfaction level with admission in emergency department was $94.4 \%$ (Shaikhi \& Javadi, 2005). It was also $86.5 \%$ in a study carried out by Ansari et al at Iran University of Medical Science (Ansari, Ebadi, \& Molasadeghi, 2005). In another study in 2007, satisfaction level with services was 72.9\% (Moshiri, Nourbakhsh, Ghafari, \& Shafie, 2011).

Initial electronic search revealed that different studies have been carried out concerning patients' satisfaction with services at clinics and emergency centers of hospitals; combining findings of these studies, precious results will be extracted which will be a valuable criterion for policymakers and programmers due to their high reliability. Thus, authors tried to review all available studies systematically and to combine them using meta-analysis so as to evaluate patients' satisfaction with emergency departments of Iran with regard to considerations related to the heterogeneity of studies.

\section{Methods}

The aim of the present study was to determine patients' satisfaction level with emergency departments of hospitals in Iran; to do this, previous documents were reviewed.

\subsection{Search Strategy}

In this research, to find studies published electronically until December 2013, articles published in domestic and foreign journals as well as those available in Persian data bases of SID (www.sid.ir), Iranmedex (www.iranmedex.com), Magiran (www.magiran.com), Medlib (www.medlib.ir) and English database of PubMed and Google Scholar were used. In this search, Persian and English keywords and probable combination of main and important words were searched. These search was done with keywords of "Satisfaction, Emergency, hospital, Patient, Iran/Iranian and plus names of provinces and conjunctions "and/or". The Persian Keywords were equivalent to their English counterparts and all probable combinations were considered. This search was carried out in December 2013. Also, reference list of published studies was evaluated to increase sensitivity and to select more studies. Search evaluation was done randomly by an independent researcher and it was confirmed that no studies were excluded.

\subsection{Studies Selection}

Entire text or summary of all searched articles, documents and reports were extracted. After reviewing and studying titles of documents, the repeated items were excluded; then, texts of articles were carefully studied by researchers and the related articles were selected and irrelevant ones were excluded.

\subsection{Quality Evaluation}

Having determined the related studies in terms of titles and contents, a checklist which was used in previous study (Moosazadeh, Nekoei-moghadam, Emrani, \& Amiresmaili, 2014), was applied to evaluate the quality of documents; objective of every research, study method, sample size, sampling method, data collection tool, variables evaluation status and analysis status were examined using 12 questions (one score for each question) (Table 2).

According to this checklist, maximum score is 12 (Moosazadeh, Nekoei-moghadam, Emrani, \& Amiresmaili, 2014). Finally, the primary articles which obtained score 8 and more, were selected and the related information was extracted and analyzed.

\subsection{Studies Inclusion Criteria}

All Persian and English studies which, attained the predetermined score of eight and which determined the rate of hospital emergency patient satisfaction of Iran were included.

\subsection{Studies Exclusion Criteria}

After reviewing and examining articles or abstract of articles and after recognizing disagreements, following studies were excluded:

A) Studies that did not report overall satisfaction of patients from the emergency departments, B) studies which sample size was not specified, C) proceedings of congresses and conferences which full texts were not available. 


\subsection{Data Extraction}

Data was extracted by researchers in terms of title, first author, publication year, total sample size, sample size by gender, research method, research place, total rate of satisfaction and rate of satisfaction in terms of gender. Data was entered into Excel spreadsheet.

\subsection{Analysis}

Data was entered into Stata software for analysis. Standard error of patient's satisfaction level in each study was calculated using the binomial distribution formula. Finally, the heterogeneity index was determined among studies using the Cochran test $(\mathrm{Q})$ were determined. Based on the heterogeneity results with meta-command (meta) in the meta-analysis, random effect model was used to estimate total satisfaction level of patients with the emergency rooms in Iran. In addition, to minimize the random distribution between point estimates of the studies, the findings of all studies were adjusted using Bayesian analysis. Finally, the effects of variables which had been determined as possible sources of heterogeneity were examined in stata 11 software using Meta-regression method. Spot estimates of patients' satisfaction level with emergency rooms were calculated at forest plots (confidence interval=95\%). In this graph, size of the square represents weight of each study and lines at both sides of the square show confidence interval of $95 \%$.

\section{Results}

Using the related keywords with the maximum sensitivity, 16022 articles were found in national and international electronic databases; limiting the keywords and increasing search properties, 1246 articles were selected. Of them, 146 cases were excluded due to duplication. Titles and abstracts of 1082 articles were assessed, and 973 unrelated cases were excluded. Then, full texts of 109 articles were reviewed and 75 unrelated cases were omitted again. 34 related articles were evaluated with a checklist of quality control and inclusion and exclusion criteria. Of them, 10 articles were excluded due to some reasons including failure to achieve minimum score of quality assessment, unclear sample size and unclear percentage of satisfaction with emergency rooms of hospitals. Finally, 24 articles were entered into the meta-analysis. The references of articles were also reviewed in order to increase the sensitivity of the search, but no new article was found (Figure 1, Table 1).

All initial studies which were entered into the meta-analysis were of descriptive-analytic type. Random sampling method (simple or systematic) had been used in 15 studies; stratified sampling method had been used in 2 studies, simple method in one case; sequential sampling method in one study; and 5 studies had unclear sampling method. A checklist was used to collect data in all studies. Its validity had been reported in 18 studies. It should be noted here that content of the checklist used in the initial studies was different. The aim of all studies was to determine patients' satisfaction level with the way services were presented in emergency centers of hospitals.

Total number of samples examined in initial studies which were entered into the meta-analysis was 11,168 patients. Only 12 studies reported their sample size by sex (2215 males and 2385 females). The highest sample size was related to a study carried out by Zahmatkesh in Golestan Province $(\mathrm{N}=2,400)$ and the lowest one was related to a study by Peyrovi in Tehran $(\mathrm{N}=20)$. The lowest and highest satisfaction level was 24 (Zahmatkesh, Hajimoradloo, Kazemi Malekmahmoodi, \& Khoddam, 2010) and 98.4\% (Sarchami, \& Sheikhi, 2006) respectively.

This meta-analysis revealed that patients' total satisfaction with emergency sections of hospitals in Iran was $68.9 \%$ (57.2-80.7) based on the random effect model (according to presence of heterogeneity in initial studies) (Figure 2). In order to study the effects of initial studies on heterogeneity, sensitivity analysis was also done. Although heterogeneity level decreased drastically after recognizing and excluding some studies, it still existed. After studies affecting heterogeneity were excluded, total satisfaction with emergency departments was 70.9 (66.1-75.6) (Figure 3). Using meta-regression, publication year was examined as one of the possible sources of heterogeneity; it had no significant effect on heterogeneity of initial studies $(\mathrm{P}=0.2, \mathrm{~B}=-1.3)$. 
Table 1. Patient satisfaction percent with Iranian hospitals emergency departments according to studies entered to meta-analysis and pooled estimation

\begin{tabular}{|c|c|c|c|c|c|c|c|c|}
\hline \multirow{2}{*}{ ID } & \multirow{2}{*}{ First author } & \multirow{2}{*}{$\begin{array}{l}\text { publication } \\
\text { year }\end{array}$} & \multirow{2}{*}{$\begin{array}{l}\text { Location } \\
\text { of study }\end{array}$} & \multirow{2}{*}{$\begin{array}{l}\text { Average or } \\
\text { range of age }\end{array}$} & \multicolumn{3}{|c|}{ Sample size } & \multirow{2}{*}{ Satisfaction level } \\
\hline & & & & & Male & Female & Total & \\
\hline 1 & Omidvari & 2008 & Tehran & $47.3 \pm 16.39$ & 84 & 69 & 153 & 41.8 \\
\hline 2 & Sarchami & 2000 & Ghazvin & NA* & 343 & 650 & 993 & 98.4 \\
\hline 3 & Ansari & 2004 & Tehran & $1-75$ & 37 & 365 & 402 & 80.7 \\
\hline 4 & Ebrahimnia & 2007 & Tehran & $\mathrm{NA}^{*}$ & 227 & 132 & 360 & 82.4 \\
\hline 5 & Khashjan & 2005 & Tehran & NA* & NA* & $\mathrm{NA}^{*}$ & 759 & 80.7 \\
\hline 6 & Dirkavand & 2010 & Ilam & $\mathrm{NA}^{*}$ & $\mathrm{NA}^{*}$ & $\mathrm{NA}^{*}$ & 100 & 78 \\
\hline 7 & Peyrovi & 2009 & Tehran & $45.32 \pm 16.06$ & NA* & $\mathrm{NA}^{*}$ & 20 & 67.4 \\
\hline 8 & Zahmatkesh & 2006 & Golestan & $35.5 \pm 15.6$ & NA* & $\mathrm{NA}^{*}$ & 2400 & 24 \\
\hline 9 & Roodbari & 2008 & Zahedan & NA* & NA* & $\mathrm{NA}^{*}$ & 300 & 80.5 \\
\hline 19 & Entezari Asl & 2000 & Ardabil & NA* & 60 & 40 & 600 & 78.1 \\
\hline 11 & Nooralsana & 2012 & Fasa & $36.4 \pm 12.1$ & 235 & 235 & 470 & 77.5 \\
\hline 12 & Nasiriani & 2008 & Yazd & 38 & 53 & 47 & 100 & 67.5 \\
\hline 13 & Golafrooz & 2001 & Sabzevar & $1-90$ & NA* & $\mathrm{NA}^{*}$ & 193 & 95.3 \\
\hline 14 & Kianmehr & 2008 & Tehran & $\mathrm{NA}^{*}$ & NA* & $\mathrm{NA}^{*}$ & 638 & 62 \\
\hline 15 & Seydi & 2006 & Ghom & $\mathrm{NA}^{*}$ & NA* & $\mathrm{NA}^{*}$ & 180 & 71.14 \\
\hline 16 & Sheykhi & 2000 & Ghazvin & $15-24$ & 42 & 29 & 71 & 59 \\
\hline 17 & Shojaii & 2008 & Kerman & $31.3 \pm 14.3$ & 257 & 133 & 390 & 75.3 \\
\hline 18 & Soleimanpour1 & 2008 & Tabriz & $\mathrm{NA}^{*}$ & 175 & 128 & 303 & 62 \\
\hline 19 & Saadati & 2004 & Mashhad & NA* & 406 & 326 & 732 & 61.7 \\
\hline 20 & Soleimanpour2 & 2011 & Tabriz & $\mathrm{NA}^{*}$ & 296 & 204 & 500 & 63.2 \\
\hline 21 & Jalili & 2006 & Tehran & 42.5 & $\mathrm{NA}^{*}$ & $\mathrm{NA}^{*}$ & 317 & 56.61 \\
\hline 22 & Kazemifard & 2011 & Jahrom & $\mathrm{NA}^{*}$ & $\mathrm{NA}^{*}$ & $\mathrm{NA}^{*}$ & 526 & 80.2 \\
\hline 23 & Abrakht & 2011 & Booshehr & NA* & NA* & $\mathrm{NA}^{*}$ & 483 & 35 \\
\hline \multirow[t]{2}{*}{24} & Janati & 2011 & Tabriz & NA* & $\mathrm{NA}^{*}$ & $\mathrm{NA}^{*}$ & 178 & 76 \\
\hline & Pooled estimate & - & - & - & 2215 & 2385 & 11168 & $68.9(57.2-80.7)$ \\
\hline \multirow[t]{2}{*}{ Total } & \multirow{2}{*}{$\begin{array}{l}\text { Heterogeneity } \\
\text { test }\end{array}$} & $\begin{array}{l}\text { Chi- } \\
\text { square(Q) }\end{array}$ & - & - & - & - & - & $7272(\mathrm{P}<0.001)$ \\
\hline & & I-Square & - & - & - & - & - & $99.7 \%(\mathrm{P}<0.001)$ \\
\hline \multirow{3}{*}{$\begin{array}{l}\text { Total(after } \\
\text { removal of } \\
\text { the outlier } \\
\text { data) }\end{array}$} & Pooled estimate & - & - & - & - & - & - & $70.9(66.1-75.6)$ \\
\hline & \multirow{2}{*}{$\begin{array}{l}\text { Heterogeneity } \\
\text { test }\end{array}$} & $\begin{array}{l}\text { Chi- } \\
\text { square(Q) }\end{array}$ & - & - & - & - & - & $314.7(\mathrm{P}<0.001)$ \\
\hline & & I-Square & - & - & - & - & - & $95.2 \%(\mathrm{P}<0.001)$ \\
\hline
\end{tabular}

*: Not Available. 
Table 2. Checklist to assess the primary studies

\begin{tabular}{|c|c|c|c|}
\hline \multirow{2}{*}{ No } & \multirow{2}{*}{ Questions } & \multicolumn{2}{|l|}{ Score } \\
\hline & & yes $=1$ & $\mathrm{No}=0$ \\
\hline 1 & Are the research questions or objectives clearly stated? & & \\
\hline 2 & Is the study context clearly described? & & \\
\hline 3 & is the sample size stated? & & \\
\hline 4 & $\begin{array}{l}\text { Is the calculation of sample size clearly described (is the sample size appropriate According to } \\
\text { the research question and variables?) }\end{array}$ & & \\
\hline 5 & Is the sampling method clearly described? & & \\
\hline 6 & Is the sampling strategy appropriate for the research question? & & \\
\hline 7 & Is the method of data collection clearly described? & & \\
\hline 8 & Is the data collection method appropriate to the research question? & & \\
\hline 9 & Is the method of analysis clearly described? & & \\
\hline 10 & Are the research results clearly stated? & & \\
\hline 11 & Is the analysis appropriate for the research question? & & \\
\hline 12 & Are the claims made supported by sufficient evidence? & & \\
\hline
\end{tabular}




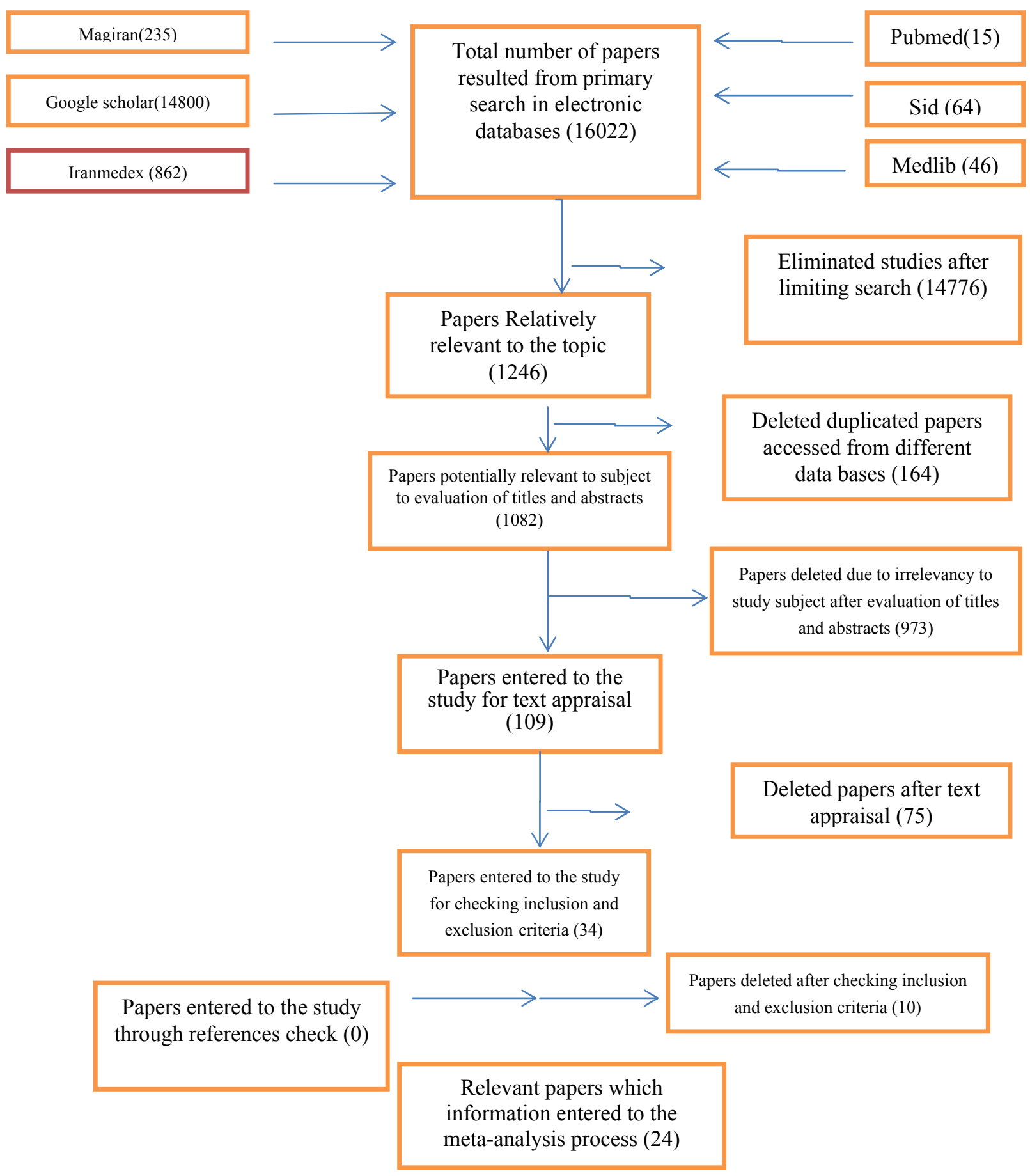

Figure 1. Papers search and review flowchart 


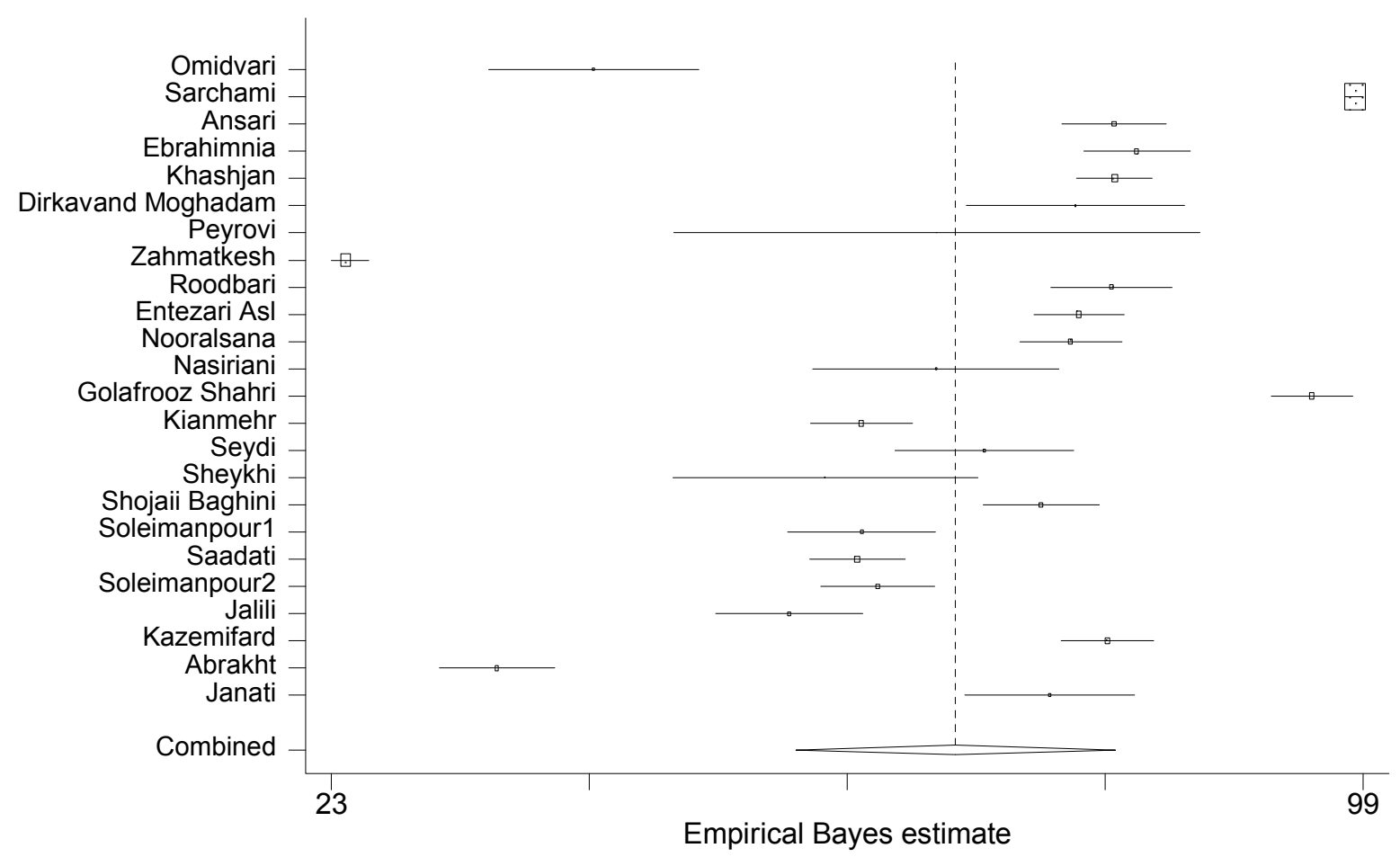

Figure 2. Distribution of the adjusted percent of patient satisfaction in each study and overall; This chart shows that the range of patient satisfaction percent in each study is $24.04-98.39 \%$ before removing outlier data, pooled estimate: $68.9 \%(57.2-80.7), \mathrm{I} 2=99.7 \%$

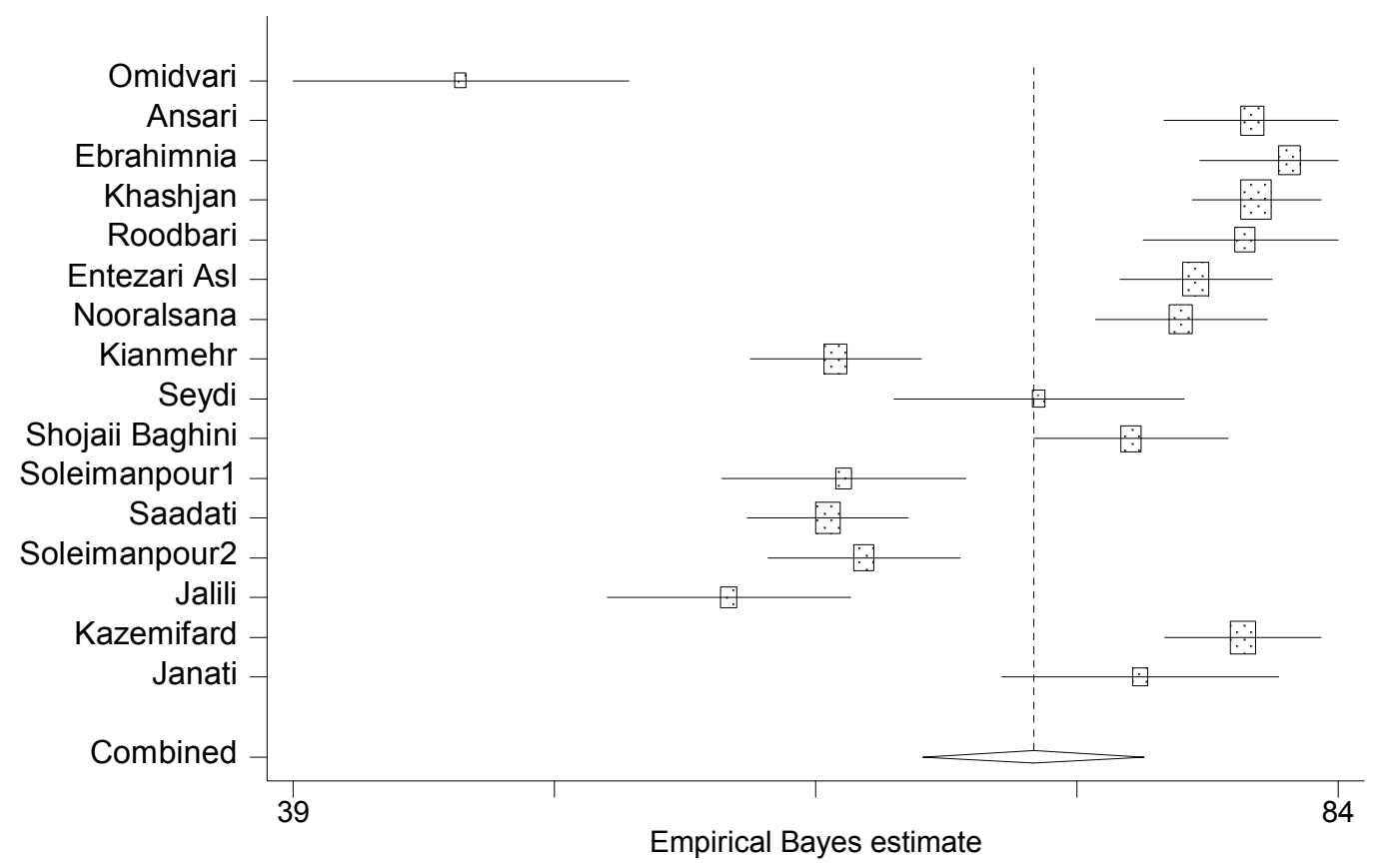

Figure 3. Distribution of the adjusted percent of patient satisfaction in each study and overall; This chart shows that the range of patient satisfaction percent in each study is $46.2-81.9 \%$ after removing outlier data, pooled estimate: $70.9 \%(66.1-75.6), \mathrm{I} 2=95.2 \%$ 


\section{Discussion}

This meta-analysis determined patients' total satisfaction with the way services were presented and with the quality of services in hospital emergency rooms in Iran. According to the results of this meta-analysis, patients' satisfaction level with services presented at hospital emergency rooms was 70.9 with regard to the heterogeneity of the studies and based on the random effect model.

In a study conducted by Abolhasani \& Tavakol in 1994 in Hamedan, satisfaction level of patients' relatives with services presented at emergency rooms was $47.1 \%$ (Abolhassani \& Tavakol, 1994). Moreover, it has been shown in studies conducted in western countries that culture of the society and interaction with patients affect patients' satisfaction (Taylor \& Benger, 2004). In a study by Shaikhi and Javadi, patients' satisfaction level with admission at the emergency rooms was $94.4 \%$ (Shaikhi \& Javadi, 2005). In another study conducted by Ansari et al in 2004 in Iran University of Medical Science, total satisfaction level with emergency services and emergency admission services was 80.7 and $86.5 \%$ respectively. In his study, Ansari stated that high treatment costs at emergency centers, buying equipment, waiting at emergency rooms, not using curtains or partitions and bad conditions of emergency rooms were the most important reasons of dissatisfaction (Ansari, Ebadi, \& Molasadeghi, 2005). In his study, Shojaie Baghini et al reported that total satisfaction level with emergency rooms was 75.3\% (Shojaee Baghini, Nakhei, Bahrampour, Namazian, \& Mehrabian, 2008). High satisfaction level in the above study may be due to the differences in people's culture, their demands, and differences in number of people referring to emergency rooms (Vieth \& Rhodes, 2006) or differences in quality of the presented services (Cassidy-Smith, Baumann, \& Boudreaux, 2007).

In a study by Shojaie Baghini, a significant relationship was observed between age, referral reason and satisfaction level $(\mathrm{P}=0.008)$; as age and health status improve, satisfaction level increases.Also, there was a significant relationship between number of referrals to emergency departments $(\mathrm{P}=0.01)$ and hospitalization $(\mathrm{P}=0.01)$ and satisfaction of patients' relatives (Shojaee Baghini, Nakhei, Bahrampour, Namazian, \& Mehrabian, 2008). In studies conducted in developed countries, age is a factor influencing clients' satisfaction with services presented in emergency rooms (Taylor, \& Benger, 2004). In a study which examined the quality of care in 13 emergency centers in Canada, satisfaction level was $73.1 \%$ (Hutchison et al., 2003).

Results of similar studies show that satisfaction of patients hospitalized in emergency centers of Ahvaz hospitals was $86 \%$ (Taheri, Fereydounimoghadam, Cheraghian, \& Khazani, 2010); and it was $98.4 \%$ in treatment-educational centers affiliated to Qazvin University of Medical Science and Health-Treatment Services (Sarchami \& Shakhi, 2003). This difference in satisfaction level may be due to difference in subjects, types of questions and scales as well as ignoring private hospitals and shortage of number and physical space of emergency centers.

In their study, Thomas et al reported that the effect of equipment and tools of emergency centers and presence of necessary drugs were $96.0 \%$ and $85 \%$ respectively (Thomas et al., 1995). This difference in satisfaction level may be due to some factors including cultural differences and familiarity of patients and their relatives with their rights. Karimollahi and Mazaheri reported that access to emergency rooms, cleanness, temperature, ventilation and conditions of bathrooms were the factors affecting patients' satisfaction (Karimollahi \& Mazaheri, 2000).

In a study by Sarchemi, satisfaction level with emergency centers (98.4) was significantly different in terms of hospital, sex and age of patients, number of referrals to emergency centers, insurance type and status and patient's fate (Sarchami \& Shakhi, 2003).

Like results of some studies done in other countries, results of a study carried out by Omidvari reflected the relationship between age, gender, educational level and length of stay and patients' satisfaction with the care they had received (Omidvari et al., 2008).

Using a structured search of all available initial studies, the present meta-analysis tried to depict a clear image of patients' satisfaction with emergency rooms of hospitals in Iran by reviewing quality of initial studies, excluding unrelated studies and increasing power of the studies by employing high sample volumes. Thus, this evaluation can be used by policy makers and programmers.

One of the limitations of the present study which was related to the initial studies was scattered variables and different contents of information collection tools; it affected total satisfaction level reported in every study and was considered a possible source of heterogeneity. Another possible limitation was lack of access to certain documents because they were not published. It should be noted that although sex could be a factor affecting satisfaction level, evaluating this index was impossible because satisfaction level had not been reported in terms of sex. Another limitation was that initial studies focused in a limited number of provinces (14 provinces), and it 
was not taken into account in many provinces despite the importance of emergency centers.

\section{Conclusion}

This meta-analysis showed that patients' satisfaction with the performance of hospitals and the way services were presented in emergency centers in hospitals of Iran was desirable. Concerning multifactorial nature of patients' satisfaction, it is necessary to take this matter into regular and routine consideration. It is suggested that future studies will focus on all provinces and that patients' satisfaction will be determined and compared in both private and governmental hospitals.

\section{References}

Abol-Hassani, F., \& Tavakol, M. (1994). A survey of satisfaction of people accompanying the patient in Emergency Department. Sci J of Hamadan Uni of Med Sci and Health Servi, 2, 10-14.

Amiresmaili, M., \& Moosazadeh, M. (2013). Determining job satisfaction of nurses working in hospitals of Iran: A systematic review and meta-analysis. Iranian J Nursing Midwifery Res, 18, 343-348.

Ansari, H., Ebadi, F., \& Molasadeghi, G. (2005). Patient satisfaction of Iran University of medical sciences. Birjand Univ Med Sci J, 11, 38-45.

Carter, E. J., Pouch, S. M., \& Larson, E. L. (2013). The Relationship Between Emergency Department Crowding and Patient Outcomes: A Systematic Review. J Nurs Scholarsh, 19.

Cassidy-Smith, T. N., Baumann, B. M., \& Boudreaux, E. D. (2007). The Disconfirmation Paradigm: Throughput times and emergency department patient satisfaction. $J$ Emerg Med, 32, 7-13. http://dx.doi.org/10.1016/j.jemermed.2006.05.028

Ekwall, A. (2013). Acuity and anxiety from the patient's perspective in the emergency department. $J$ Emerg Nurs, 39, 534-538. http://dx.doi.org/10.1016/j.jen.2010.10.003

Gilleard, C., \& Reed, R. (1998). Validitating a measure of patient satisfaction with community nursing services. $J A N, 28,94-99$. http://dx.doi.org/10.1046/j.1365-2648.1998.00773.x

Hutchison, B., Ostbye, T., Barnsley, J., Stewart, M., Mathews, M., Campbell, M. K., et al. (2003). Patient satisfaction and quality of care in walk-in clinics family practices and emergency departments: The Ontario walk in clinic study. CMAJ, 168, 977-983.

Ivy, C. H., Jacques, L., Nicole, M., Jeffrey, T., Sharon, R., Alex, K., et al. (2013). Implementing wait-time reductions under Ontario government benchmarks (Pay-for-Results): a Cluster Randomized Trial of the Effect of a Physician-Nurse Supplementary Triage Assistance team (MDRNSTAT) on emergency department patient wait times. BMC Emergency Medicine, 13, 1-10.

Karimollahi, M., \& Mazaheri, E. (2000). Factors affecting satisfaction of patients in emergency medical sciences. Iranian $J$ of health \& care, 3, 24-30.

Lau, F. L. (2000). Can communication skills workshops for emergency department doctors improve patient satisfaction? Emerg Med J, 17, 251-253. http://dx.doi.org/10.1136/emj.17.4.251.

Mackinley, R. K., \& Roberts, C. (2001). Patient satisfaction with out of hours primary medical care. Qual Health Care, 10(1), 23-8. http://dx.doi.org/10.1136/qhc.10.1.23.

Moosazadeh, M., Nekoei-moghadam, M., \& Amiresmaili, M. R. (2013). Determining the Level of Hospitalized Patients Satisfaction of Hospitals: A Systematic Review and Meta-Analysis. Hospital, 12(1), 77-87.

Moosazadeh, M., Nekoei-moghadam, M., Emrani, Z., \& Amiresmaili, M. (2014). Prevalence of unwanted pregnancy in Iran: A systematic review and meta-analysis. Int J Health Plann Manage, 29(3), e277-290. http://dx.doi.org/10.1136/qhc.10.1.23.

Moshiri, E., Nourbakhsh, M., Ghafari, M. S., \& Shafie, M. R. (2011). The comparison of satisfaction of patients referring to the emergency departments of hospitals in Arak during 2006-7 and 2009. Arak Med Uni J, 14, $85-91$.

Omidvari, S., Shahidzadeh, A., Montazeri, A., Azin, S.A., Harirchi, A. M., \& Souri, H. (2008). Patient satisfaction survey in the hospitals of Tehran University of medical Sciences, Tehran, Iran. Payesh, 2, 141-152.

Sarchami, R., \& Shakhi, M. R. (2003). Consideration of the satisfaction amount of patients who reffered to the remedial and instruction center of Qazvin. Publication of behavioral sciences researches, 1, 42-45. 
Shaikhi, M., \& Javadi, A. (2005). Patient satisfaction of health care services provided in Ghazvin educational-health centers. Ghazvin Univ Med Sci J, 29, 62-6.

Shojaee-Baghini, H., Nakhei, N., Bahrampour, M. R., Namazian, R., \& Mehrabian, S. (2008). Evaluation of patient satisfaction with emergency department in Bahonar hospital of Kerman. $J$ of Nurs and Mid, 8, $50-55$.

Taheri, N., Fereydounimoghadam, M., Cheraghian, B., \& Khazani, S. (2010). Patient satisfaction of emergency medical services in Abadan and khorramshahr Hospitals, 2009. J Urmia Nursing and Midwifery Faculty, 4(8), 44-53.

Taylor, C., \& Benger, J. R. (2004). Patient satisfaction in emergency medicine. Emerg Med J, 21, 528-532. http://dx.doi.org/10.1136/emj.2002.003723.

Thomas, L. H., Macmilan, J., McCall, E., Pries, J., Hale, C., \& Bond, S. (1995). Obtaining patients View of nursing care to inform the development of a patient satisfaction scale. Int $J$ for quality in health care, 2 , 53-163.

Trout, A., Magnusson, A. R., \& Hedges, J. R. (2000). Patient satisfaction investigations and the emergency department. What does the literature say? Acad Emerg Med, 7, 695-709. http://dx.doi.org/10.1111/j.1553-2712.2000.tb02050.x.

Vieth, T. L., \& Rhodes, K. V. (2006). The effect of crowding on access and quality in an academic ED. Am J Emerg Med, 24, 787-794. http://dx.doi.org/10.1016/j.ajem.2006.03.026.

Yekkeh, F. (2006). Evaluation of quality and nursing skills in emergency department. Holist Nurs Midwifery, 16(1), 39-42.

Zahmatkesh, H., Hajimoradloo, N., Kazemi-Malekmahmoodi, S., \& Khoddam, H. (2010). The assessment of patients satisfaction of hospital emergency departments-Golestan. J Gorgan Uni Med Sci, 12, 91-96.

\section{Copyrights}

Copyright for this article is retained by the author(s), with first publication rights granted to the journal.

This is an open-access article distributed under the terms and conditions of the Creative Commons Attribution license (http://creativecommons.org/licenses/by/3.0/). 